\title{
Faktor-faktor pendukung membuka usaha bagi pekerja pariwisata yang dirumahkan di kota denpasar
}

\author{
A.A Manik Pratiwi ${ }^{1)}$, Putu Diah Kesumadewi ${ }^{2)}$ \\ Fakultas Pariwisata, Universitas Udayana \\ a.manikpratiwi@unud.ac.id, diahkusumadewi@unud.ac.id
}

\begin{abstract}
Abstrak
Seiring dengan meningkatnya pekerja pariwisata yang dirumahkan akibat Covid - 19, maka penelitian inibertujuan untuk 1) faktor-faktor yang merupakan faktor pendukung m embuka usaha bagi pekerja pariwisa ta y ang dirumahkan di Kota Denpasar, 2) untuk mengetahuifaktor yang paling dominan yang merupakan faktor pendukung membuka usaha bagi pekerja pariwisata yang dirumahkan di Kota Denpasar. Penelitian inimenggunakan 100 responden dengan teknik a ccid ental sa mpling. Data akan dianalisis menggunakan analisis deskriptif kuantitatif dan menggunakan analisis faktor. Berdasarkan hasil perhitungan dengan menggunakan analisis faktor terdapat 12 variabel yang dikelom pokkan ke dalam 3 faktor, yaitu faktor hubungan bisnis da n manajemen u saha, faktor internal dan eksternal, dan faktor motivasi diri yang merupakan faktor pendukung membuka u saha bagi pekerja pariwisata yang dirumahkan di Kota Denpasar. Da ri ketiga faktor tersebut, faktor hubungan bisnis dan manajemen usaha yang paling dominan. Perlu dia dakan kegiatan pelatihan kewirau sahaan bagi pekerja pariwisata yang dirumah kan agar m ereka memiliki ke terampila $n$ wira sa ha yang sangat bermanfaat untuk menjalankan usaha.
\end{abstract}

Keywords : Analisis fa ktor, bisnis pariwisa ta, pekerja dirumahkan.

\begin{abstract}
As a result of Covid-19, many countries have closed international airports, this of course has a huge im pact on the tourism sector in Bali. Since April 2020, nearly 96 percent of hotels in Bali have closed and la id off their workers. The sta tus of these workers was laid off (taking unpaid leave). Tourism workers who lost their jobs did not just give up, they do every thing to make money. Many of the la id -off tou rism workers have switched professions to become new seller who use their cars and selling on the side of the main road in Denpasar City. This study aims 1) to find supporting factors in opening a business for laid-off tourism workers during the Covid -19 pandemic, 2) to find out the most dominant factor which is a supporting factor in opening a business for laid-off tourism workers during the Covid-19 pandemic. Research location in Denpasar City. This study used 100 respondents with accidental sampling technique. The data will be a nalyzed using quantitative descriptive analysis and factor analy sis. Based on the results of calculations using factor analysis, there are 12 variables grouped into 3 factors, namely business relations and business management factors, internal and externalfactors, and self-motivation factors which are supporting factors in opening a business for laid-off tourism workers during the Covid-19 pandemic. Of the three factors, business relations and business management are the most dominant. Conclu sions from this research need to be hold entrepreneurship training activities for laid-off tourism workers so that they have entrepreneurial sk ills that a re very useful for develop their business.
\end{abstract}

Keywords : supporting, factors, business, laid-off, tourism, workers.

\section{PENDAHULUAN}

Industri pariwisata merupakan industri yang sangat rentan terhadap kondisi disekitarnya. Bali yang mengandalkan pertumbuhan ekonomi dari industri pariwisata telah beberapa kali mengalami keterpurukan ekonomi akibat sektor pariwisata yang mengalami guncangan. Guncangan yang hebat pada sektor pariwisata Bali terjadi pada tahun 2002 yaitu adanya Bom Bali I dan pada tahun 2005 terjadi Bom Bali II. Adanya travel warning ke Bali yang dikeluarkan oleh pemerintah negara-neagara asal wisatawan mancanegara seperti Australia, Eropa, dan Amerika membuat jumlah wisatawan asing yang datang ke 
Bali menurun, dan ini berdampak pada tingkat hunian hotel yang menurun hingga 20 persen. Hal ini mengakibatkan banyak pekerja pariwisata yang dirumahkan. Pada tahun 2017, Gunung Agung kembali meletus, Erupsi Gunung Agung kembali meyebabkan penurunan kunjungan wisatawan mancanegara. Hal ini kembali mengguncang sektor pariwisata Bali, namun dengan adanya promosi pariwisata Bali yang menyatakan bahwa Bali aman karena banyak destinasi pariwisata yang lokasinya jauh dari Gunung Agung mengakibatkan industri pariwisata cepat kembali pulih.

Saat ini dunia sedang menghadapi pandemi Covid-19. Akibat Covid-19, banyak negaranegara yang melakukan penutupan Bandara Internasional, hal ini tentu sangat berdampak pada sektor pariwisata Bali. Sejak April 2020, hampir 96 persen hotel di Bali tutup dan merumahkan pekerjanya. Status pekerja tersebut ada yang di PHK dan dirumahkan (mengambil cuti tidak dibayar). Pekerja pariwisata yang kehilangan pekerjaannya tidak meyerah begitu saja. Mereka mengerjakan semua yang dapat dilakukan untuk menghasilkan uang. Banyak dari pekerja pariwisata yang dirumahkan tersebut beralih profesi menjadi pedagang yang menggunakan mobilnya dan berdagang di pinggir jalan utama di Kota Denpasar. Barang yang dijual yaitu barang-barang rumah tangga, makanan, hingga pakaian.

Tidak mudah memulai membuka usaha bagi pekerja pariwisata yang dirumahkan, hal ini karena biasanya mereka telah biasa menerima gaji tetap tiap bulannya. Untuk membuka usaha diperlukan niat untuk berwirausaha dan mengasah ketrampilan berwirausaha. Selain niat dan ketrampilan menjadi wirausaha, terdapat juga faktor-faktor pendukung dalam membuka usaha.

Seiring dengan meningkatnya pekerja pariwisata yang dirumahkan membuka usaha maka penelitian ini bertujuan untuk 1) faktor-faktor yang merupakan faktor pendukung membuka usaha bagi pekerja pariwisata yang dirumahkan di Kota Denpasar, 2) untuk mengetahui faktor yang paling dominan yang merupakan faktor pendukung membuka usaha bagi pekerja pariwisata yang dirumahkan di Kota Denpasar. Judul tabel berada di atas, sedangkan judul gambar ditulis di bawah. Contoh penempatan tabel dan gambar adalah di tengah-tengah halaman sebagai berikut.

\section{METODE PENELITIAN}

Jenis penelitian ini merupakan penelitian dengan pendekatan kuantitatif yang dilakukan dengan teknik pengumpulan data melalui pengamatan langsung (observasi), wawancara mendalam (depth interview), penyebaran angket (questioner). Penyajian hasil analisis data dapat dilakukan, baik secara formal (dalam bentuk tabel) maupun informal (dalam bentuk naratif). Teknik analisa data yang digunakan adalah Deskriptif Kuantitatif, Skala Likert, dan Analisis Faktor.

\section{HASIL DAN PEMBAHASAN}

\subsection{Karakteristik Responden Penelitian}

Dalam penelitian ini penulis menggunakan 100 responden, yaitu responden yang merupakan pekerja pariwisata yang dirumahkan di Kota Denpasar. Responden perempuan berjumlah 63 orang dengan persentase $63 \%$ dan responden laki-laki berjumlah 37 orang dengan persentase $37 \%$. jumlah responden terbanyak terdapat dalam kelompok usia 21 25 tahun, yaitu berjumlah 36 orang dengan persentase $36 \%$. Jumlah responden terbany ak merupakan responden yang memiliki pendidikan terakhir Diploma IV/ S1 sebanyak 48 
orang dengan persentase $48 \%$. Responden yang sebelumnya bekerja di hotel sebanyak 57 $\%$ dan pekerjaan pekerja pariwisata sebelum dirumahkan sebanyak 69 orang atau $69 \%$ sebagai pekerja di bagian operasional hotel.

\subsection{Faktor - Faktor Pendukung Membuka Usaha bagi Pekerja Pariwisata yang dirumah kan di Kota Denpasar}

Dari hasil analisis jumlah faktor yang didasarkan pada Principle Component Analysis (PCA) dari 12 variabel terbentuk sebanyak 3 faktor.

TABEL 1. ROTASI FAKTOR DENGAN METODE VARIMAX

\begin{tabular}{|c|c|l|c|}
\hline No & Faktor & \multicolumn{1}{|c|}{ Variabel } & $\begin{array}{c}\text { Faktor } \\
\text { Loading }\end{array}$ \\
\hline 1 & 1 & Hubungan baik dengan pemasok dan distributor & 0,899 \\
\hline 2 & & administrasi yang baik & 0,772 \\
\hline 3 & & perencanaan yang jelas & 0,739 \\
\hline 4 & & keuangan yang lancar & 0,648 \\
\hline 5 & & struktur organisasi usaha yang baik & 0,572 \\
\hline 6 & 2 & lokasi yang strategis & 0,827 \\
\hline & & Peraturan Pemerintah, Politik, Sosial, Ekonomi dan & \\
\hline 7 & & Budaya Lokal yang mengembangkan kewirausahan & 0,821 \\
\hline 8 & & kualitas produk yang baik & 0,44 \\
\hline 9 & & catatan bisnis yang baik & 0,406 \\
\hline 10 & 3 & tekad dan kerja keras & 0,809 \\
\hline 11 & & kesempatan dan peluang & 0,767 \\
\hline 12 & & kemampuan dan kemauan yang kuat & 0,607 \\
\hline
\end{tabular}

Sumber: Hasilpengolahan data (2021)

Faktor pertama yang menempati ranking tertinggi dalam faktor-faktor pendukung membuka usaha bagi pekerja pariwisata yang dirumahkan di Kota Denpasar adalah faktor hubungan bisnis dan manajemen usaha. Faktor tersebut memiliki nilai eigenvalue terbesar yaitu 5,387 dan mampu menjelaskan keragaman (varian) dari variabel-variabel yang diobservasi sebesar 44,895\%. Variabel yang tertingi dalam mendukung faktor ini adalah variabel hubungan baik dengan pemasok dan distributor dengan loading factor sebesar 0,899. Faktor manajemen usaha didukung oleh variabel administrasi yang baik dengan loading factor sebesar 0,772 , variabel perencaanaan yang jelas dengan loading factor sebesar 0,739, variabel keuangan yang lancar dengan loading factor sebesar 0,648, dan struktur organisasi usaha yang baik dengan loading factor sebesar 0,572.

Faktor kedua faktor-faktor pendukung membuka usaha bagi pekerja pariwisata yang dirumahkan di Kota Denpasar adalah faktor internal dan faktor eksternal. Faktor tersebut memiliki nilai eigenvalue sebesar 1,497 dan mampu menjelaskan keragaman (varian) dari variabel-variabel yang diobservasi sebesar 12,144 \%. Faktor internal yaitu lokasi yang strategis dengan loading factor sebesar 0,827 , kualitas produk yang baik dengan loading factor sebesar 0,440, dan catatan bisnis yang baik dengan loading factor sebesar 0,406. Faktor eksternal yaitu peraturan pemerintah, politik, sosial, ekonomi dan budaya lokal yang mengembangkan kewirausahaan dengan loading factor sebesar 0,821.

Faktor ketiga dalam faktor-faktor pendukung membuka usaha bagi pekerja pariwisata yang dirumahkan adalah motivasi diri. Faktor tersebut memiliki nilai eigenvalue sebesar 1,090 dan mampu menjelaskan keragaman (varian) dari variabel-variabel yang diobservasi sebesar $9,084 \%$. Variabel yang mendukung faktor ini adalah variabel tekad dan kerja keras, kesempatan dan peluang, dan kemampuan dan kemauan yang kuat dengan loading factor sebesar 0,$809 ; 0,767$; dan 0,607 . 


\section{Kesimpulan}

Berdasarkan hasil perhitungan dengan menggunakan analisis faktor terdapat 12 variabel yang dikelompokkan ke dalam 3 faktor, yaitu faktor hubungan bisnis dan manajemen usaha, faktor internal dan eksternal, dan faktor motivasi diri yang merupakan faktor pendukung membuka usaha bagi pekerja pariwisata yang dirumahkan di Kota Denpasar. Dari ketiga faktor tersebut, faktor hubungan bisnis dan manajemen usaha merupakan faktor pendukung membuka usaha yang paling dominan. Perlu diadakan kegiatan pelatihan kewirausahaan bagi pekerja pariwisata yang dirumahkan agar mereka memiliki keterampilan wirausaha yang sangat bermanfaat untuk menjalankan usaha.

\section{Ucapan Terima Kasih}

Terimakasih kepada pihak-pihak yang mendukung penulisan penelitian baik dari pihak LPPM Universitas Udayana dan Program Studi Pengelolaan Perhotelan serta Fakultas Pariwisata.

\section{DAFTAR PUSTAKA}

[1] Benedicta Prihatin Dwi, Riyanti. (2003). Kewirausahaan Dari Sudut Pandang. Psikologi Kepribadian. Jakarta : Grasindo.

[2] HC, R. Heru Kristanto. 2009. Kewirausahaan (Enterpreneurship): Pendekatan Manajemen dan Praktik. Yogy akarta: Graha Ilmu.

[3] Kasmir. 2007. Manajemen Perbankan. Jakarta: PT. RajaGraino Persada

[4] McGuckin, Frances. (2006). Ide-ide Besar Untuk Mengembangkan Usaha Kecil Anda. Jakarta: Abdi Tandur

[5] Suryana. (2013). Kewirausahaan: Kiat dan Proses Menuju Sukses Edisi 4. Jakarta: Sale mba Empat

[6] Peraturan Pemerintah Republik Indonesia No 52 Tahun 2012 tentang Sertifikasi Kompetensi dan Sertifikasi Usaha di Bidang Pariwisata.

[7] PP Pengupahan No 78 Tahun 2015, Pasal ayat (1)

[8] Undang-Undang Ketenagakerjaan No 13 Tahun 2003, Pasal 93 ayat (1)

[9] Winardi. (2003). Manajemen Perilaku Organisasi. Jakarta: Kencana. 